\title{
Determinants of Childhood Zoonotic Enteric Infections in a Semirural Community of Quito, Ecuador
}

\author{
Christopher Lowenstein, ${ }^{1}$ Karla Vasco, ${ }^{2}$ Soledad Sarzosa, ${ }^{2}$ Liseth Salinas, ${ }^{2}$ Andrea Torres, ${ }^{2}$ Melissa J. Perry, ${ }^{3}$ \\ Samuel J. Simmens, ${ }^{4}$ Gabriel Trueba, ${ }^{2}$ Joseph N. S. Eisenberg, ${ }^{5}$ and Jay P. Graham ${ }^{1 *}$ \\ ${ }^{1}$ University of California, Berkeley School of Public Health, Berkeley, California; ${ }^{2}$ Colegio de Ciencias Biologicas y Ambientales, Microbiology \\ Institute, Universidad San Francisco de Quito, Quito, Ecuador; ${ }^{3}$ Department of Environmental and Occupational Health, Milken Institute School of \\ Public Health, The George Washington University, Washington, District of Columbia; ${ }^{4}$ Department of Biostatistics and Bioinformatics, Milken \\ Institute School of Public Health, The George Washington University, Washington, District of Columbia; ${ }^{5}$ Department of Epidemiology, School of \\ Public Health, University of Michigan, Ann Arbor, Michigan
}

\begin{abstract}
Domestic animals in the household environment have the potential to affect a child's carriage of zoonotic enteric pathogens and risk of diarrhea. This study examines the risk factors associated with pediatric diarrhea and carriage of zoonotic enteric pathogens among children living in communities where smallholder livestock production is prevalent. We conducted an observational study of children younger than 5 years that included the analysis of child $(n=$ 306) and animal $(n=480)$ fecal samples for Campylobacter spp., atypical enteropathogenic Escherichia coli, Shiga toxin-producing E. coli, Salmonella spp., Yersinia spp., Cryptosporidium parvum, and Giardia lamblia. Among these seven pathogens, Giardia was the most commonly identified pathogen among children and animals in the same household, most of which was found in child-dog pairs. Campylobacter spp. was also relatively common within households, particularly among child-chicken and child-guinea pig pairs. We used multivariable Poisson regression models to assess risk factors associated with a child being positive for at least one zoonotic enteric pathogen or having diarrhea during the last week. Children who interacted with domestic animals-a behavior reported by nearly three-quarters of households owning animals-were at an increased risk of colonization with at least one zoonotic enteric pathogen (prevalence ratio $[P R]=1.56,95 \% \mathrm{Cl}: 1.00-2.42)$. The risk of diarrhea in the last seven days was elevated but not statistically significant $(\mathrm{PR}=2.27, \mathrm{Cl}: 0.91,5.67)$. Interventions that aim to reduce pediatric exposures to enteric pathogens will likely need to be incorporated with approaches that remove animal fecal contamination from the domestic environment and encourage behavior change aimed at reducing children's contact with animal feces through diverse exposure pathways.
\end{abstract}

\section{INTRODUCTION}

Diarrheal disease morbidity in children remains remarkably high in low- and middle-income countries (LMICs), despite significant prevention efforts aimed at improving water, sanitation, and hygiene (WASH) conditions. ${ }^{1,2}$ In the Americas, it is estimated that each child younger than 5 years experiences four episodes of diarrhea per year, and diarrhea remains a leading cause of mortality among children in LMICs. ${ }^{1}$ There is also a growing body of evidence that enteric infections, many of which are asymptomatic, can detrimentally affect growth and absorption of nutrients in children. ${ }^{3}$ Recent controlled trials that have aimed to reduce fecal exposures through improved WASH have not had the expected impact, ${ }^{4-6}$ and research suggests that fecal matter from domestic animals could be an important component missing from these interventions. ${ }^{7-11}$

In the United States, researchers have estimated that 14\% of enteric infections are attributable to direct contact with animals. ${ }^{12}$ In LMICs, there is evidence that human exposures to zoonotic enteropathogens, especially among children, are potentially more important, given that many people live in close contact with domestic animals. ${ }^{13,14}$ Studies have demonstrated that fecal contamination associated with animals in the household environment is an important risk factor for diarrhea and markers of environmental enteric dysfunction in children. ${ }^{15,16}$ In addition, the presence of livestock and poultry in the household environment contributes to more frequent human-animal interactions that can increase zoonotic infectious disease risks. ${ }^{7}$

*Address correspondence to Jay P. Graham, University of California, Berkeley School of Public Health, 2121 Berkeley Way West \#5302, Berkeley, CA 94720-7360. E-mail: jay.graham@berkeley.edu
There are many exposure pathways associated with domestic animals. One potential pathway is geophagy, a common behavior in young children wherein the soil consumed is often found to be contaminated with animal feces. ${ }^{7,15,16} \mathrm{Re}$ cent research has identified geophagy and chicken ownership as risk factors associated with environmental enteric dysfunction and child stunting. ${ }^{15-17}$ Researchers in India identified livestock and domestic animals as sources of fecal contamination of drinking water. ${ }^{18}$ There is the potential that exposures to zoonotic enteropathogens could grow in tandem with the concomitant increase in small-scale livestock production in LMICs, which is often promoted as a development strategy to improve nutrition and alleviate poverty. ${ }^{19,20}$ Understanding the risk factors associated with domestic animals is increasingly important because of the magnitude and growth of smallholder livestock and poultry production. ${ }^{21}$

There is evidence that domestic animals can carry zoonotic enteric pathogens that have the potential to cause diarrhea in humans, including Campylobacter spp., Shiga toxin-producing Escherichia coli (STEC) Salmonella spp., Yersinia spp., Cryptosporidium parvum, and Giardia lamblia. ${ }^{17,22-26}$ Which of these pathogens are important contributors to human disease likely depends on the setting. For example, many zoonotic enteropathogens of high relevance in high-income countries are less important in LMICs. ${ }^{27}$ Outbreaks of non-typhi Salmonella and enterohemorrhagic $E$. coli involving large numbers of cases and/or disease severity have brought a lot of attention to these organisms in high-income countries. ${ }^{28}$ Similarly, Campylobacter jejuni is a frequent gastrointestinal bacterial pathogen in humans in industrialized countries. ${ }^{29}$ Other zoonotic enteric 
pathogens such as atypical enteropathogenic E. coli (aEPEC) have been less investigated. ${ }^{30,31}$

Within LMICs, the presence of zoonotic enteric pathogens in the household environment is likely a function of which animal species are present, the diet of the household members, and WASH conditions of the animals. ${ }^{22}$ There remains a poor understanding of the significance of animal fecal contamination in domestic spaces, ${ }^{32}$ and many of the studies that assessed zoonotic enteric infections typically focused on one zoonotic enteric pathogen. ${ }^{33-36}$

In this study, we characterized the carriage of zoonotic enteric pathogens among children and domestic animals and tested the hypothesis that domestic animal ownership is associated with carriage of one or more zoonotic enteric pathogens by children. We also tested the hypothesis that domestic animal ownership is associated with self-reported diarrhea in at least one household member.

\section{MATERIALS AND METHODS}

Study design and setting. This study was conducted in Yaruquí, a semirural parish outside Quito, Ecuador, with approximately 22,000 residents. Economic activities in the parish include flower and strawberry production, large-scale poultry, and smallholder livestock production that primarily includes poultry, pigs, guinea pigs, and cows. Yaruquí consists of one urban neighborhood, El Centro, surrounded by approximately 21 rural neighborhoods where smallholder livestock production is common. We selected four neighborhoods to study in addition to El Centro, each with varying degrees of domestic animal ownership. These neighborhoods were selected based on a priori knowledge of population size and density and the amount of home-animal production. Within each neighborhood, we went door-to-door to identify all households that had at least one child younger than 5 years. From this population of households, we then recruited at random a total of 341 households to participate in the study using a convenience sampling strategy. The study population consisted of 125 households in El Centro, 65 households in Otón de Velez, 70 households in Chinangachi, 41 households in San Vicente, and 40 households in El Tejar. All recruitment and data collection occurred during the dry season (May-August) in 2014 (Otón de Velez), 2015 (Chinangachi and the northern half of El Centro), and 2016 (San Vicente, El Tejar, and the southern half of El Centro).

Household survey. A survey was administered to the youngest child's primary caretaker in each of the households enrolled in the study. The survey collected information about household demographics (e.g., gender of the child, household size, and educational attainment of the primary caretaker), characteristics of the home environment, and hygiene practices. ${ }^{37}$ Questions related to the home environment included information on crowding, housing structure, floor material, type of toilet, type of drinking water supply, water treatment, fecal management, and availability of a designated place for handwashing. Using a series of questions related to household assets (e.g., presence of a television and functioning car), we developed an asset index to assess the relative socioeconomic position of each household. ${ }^{38}$ The survey also included a module of questions related to animal ownership and animal husbandry. Specifically, we collected information on the species and the number of animals owned, animal management practices (e.g., use of antibiotics and animal fecal waste management), and the youngest child's interactions with animals. We also gathered dietary information related to preparation practices and the child's consumption of foodanimal products (e.g., eggs and milk) within the last one week before the child's feces were tested. Finally, we asked about the prevalence of diarrhea (defined as $\geq 3$ loose or liquid stools in a 24-hour period or any stool with blood) for the youngest child in the previous seven days. ${ }^{39}$ Surveys were administered by a trained local field enumerator in the local language (Spanish).

Stool collection and analysis. We collected stool samples from children and domestic animals in cases where the survey respondent reported the presence of animals currently living on the property. For domestic animals, fecal samples were collected either directly from the rectus (dogs, cats, and sheep) or from pooled fecal matter when animals were maintained in enclosures (pigs, chickens, and cows) or cages (guinea pigs, rabbits, and quails). Once collected, the stool samples were placed immediately in a cooler on ice for transportation to the laboratory. All bacterial culturing and sample preservation began less than 8 hours after collection. Fecal samples were analyzed for seven zoonotic enteropathogens: Campylobacter spp., aEPEC, STEC, Salmonella spp., Yersinia spp., C. parvum, and $G$. lamblia.

Pathotypes of $E$. coli were obtained by culturing samples on MacConkey lactose agar (Difco, Sparks, MD) (at $37^{\circ} \mathrm{C}$ for 18 hours). Lactose-fermenting colonies were plated in Chromocult $^{\circledR}$ Coliform agar (Merck KGaA, Darmstadt, Germany) to identify the B-D-glucuronidase activity. A random sample of five lactose-positive isolates were pooled, suspended in $300 \mu \mathrm{L}$ of sterile distilled water, and boiled for 10 minutes to release the DNA. The resulting supernatant was used for polymerase chain reaction (PCR) to identify eae and $b f p A$ genes for aEPEC, ${ }^{40,41}$ and $s t x-1$ and st $x-2$ for STEC, as previously described. $^{42}$

To isolate Yersinia spp., the samples were pre-enriched in PBS $1 \times$ for 21 days at $4^{\circ} \mathrm{C}$ and cultured in cefsulodinirgasan-novobiocin agar (at $28^{\circ} \mathrm{C}$ for 24 and 48 hours) (Oxoid Ltd., Basingstoke, Hampshire, England). Suggestive colonies were confirmed with oxidase (Bactident Oxidase, Merck) and RapiD-20E tests (bio Merieux, Marcy l'Etolie, France).

To recover Salmonella spp., samples were pre-enriched in selenite broth (at $37^{\circ} \mathrm{C}$ for 18 hours) and cultured in xyloselysine-deoxycholate agar (Difco) (at $37^{\circ} \mathrm{C}$ for 18 hours). Suggestive colonies were subjected to RapiD-20E tests (bio Merieux). The identification of serovars was performed by amplifying 10 pairs of primers for multiplex PCR in two separate reactions $S$. enterica serovar Typhimurium LT2 (STM) and S. enterica serovar Typhi CT18 (STY) previously described ${ }^{43}$ with modifications. The STM amplification was performed in $10 \mu \mathrm{L}$ reaction mixture with $1.4 \times$ PCR buffer, $2 \mathrm{mM} \mathrm{MgCl}$, $0.2 \mathrm{~mm}$ dNTPs, $0.3 \mu \mathrm{M}$ of each primer (STM1, STM2, STM3, STM4, and STM5), $0.75 \mathrm{U}$ GoTaq polymerase, and $1 \mu \mathrm{L}$ of DNA $(\sim 10 \mathrm{ng} / \mu \mathrm{L})$. Furthermore, the STY amplification reaction was performed in a final volume of $10 \mu \mathrm{L}$ with $1.6 \times$ reaction buffer; $2 \mathrm{mM} \mathrm{MgCl} 2 ; 0.2 \mathrm{~mm}$ dNTPs; $0.08 \mu \mathrm{M}$ of primers STY1, STY2, and STM6; $0.3 \mu \mathrm{M}$ primer STY3; $0.1 \mu \mathrm{M}$ of primer STY4; $0.75 \mathrm{U}$ GoTaq polymerase; and $1 \mu \mathrm{L}$ of DNA. Both reactions used the same amplification program with an initial denaturation at $94^{\circ} \mathrm{C}$ for 5 minutes, followed by 40 cycles of $94^{\circ} \mathrm{C}$ for 30 seconds, $62^{\circ} \mathrm{C}$ for 30 seconds, and $72^{\circ} \mathrm{C}$ for 1 minute, ending with a final extension at $72^{\circ} \mathrm{C}$ for 5 minutes. 
Electrophoresis conditions for displaying the results of STM and STY are gel with $2.5 \%$ agarose for 2 hours at $80 \mathrm{~V}$ with ethidium bromide staining.

To investigate thermophilic Campylobacter spp., samples were cultured on Campylobacter agar with $5 \%$ lysed horse blood and modified Preston Campylobacter Selective Supplement (Oxoid Ltd.) and incubated at $42^{\circ} \mathrm{C}$ during 48 hours in microaerobic conditions using CampyGen $\mathrm{CO}_{2}$ (Oxoid Ltd.). The colonies were Gram-stained and tested for oxidase (Bactident Oxidase, Merck). Campylobacter jejuni/coli were confirmed by PCR of hippuricase and aspartokinase genes according to the protocol developed by Persson and Olsen ${ }^{44}$ in 2005. Campylobacter species not belonging to $C$. jejuni/coli were identified through 16S rRNA gene sequencing in Functional Biosciences (Madison, WI) (http://functionalbio.com/web), and sequences were uploaded to GenBank (Accession numbers: KU362553KU362565p). Giardia lamblia and C. parvum were detected using ELISA (Ridascreen ${ }^{\circledR}$ Giardia, Ridascreen ${ }^{\circledR}$ Cryptosporidium, r-Biopharm, Darmstadt, Germany).

Statistical analyses. The two primary outcomes included whether a child tested positive for carrying one or more zoonotic enteropathogens and whether a child was reported to have had diarrhea in the last 7 days. The overall infection prevalence was calculated as the proportion of fecal samples found positive for any of the seven zoonotic enteric pathogens divided by the total number of samples tested. Diarrhea prevalence in the last 7 days was defined similarly based on responses to the household questionnaire. The main exposure to domestic animals was assessed using a binary variable that indicated whether or not a household reported having at least one animal in or around their home. Among those who reported having at least one animal, four additional exposures were measured: 1) does the child regularly interact with the animal(s), 2) does the child wash hands following contact with animals, 3) does the child consume products derived from the domestic animals raised on the property, and 4) do any animals defecate in spaces shared with the child. We constructed binary exposure variables from each of these four additional questionnaire items, hereafter referred to as "sub-exposures." To examine the intensity of sub-exposures in the household environment, we also constructed two additional binary variables to indicate whether at least one (versus none) or more than one (versus one or none) sub-exposure was reported.

We fit multivariable Poisson regression models with robust error variances and the log link function to estimate prevalence ratios (PRs) and 95\% Cls. We estimated bivariate relationships between the two outcomes of interest and each of the following covariates and potential confounders selected a priori based on the existing literature: child gender and age, caretaker educational attainment, household wealth (in tertiles), household size, neighborhood of residence, and presence of a family member working in food-animal production. We selected variables with significant associations in the bivariate analyses $(P<0.05)$ to include as controls in the adjusted models. Using a more traditional threshold for variable inclusion of $P<0.20$ resulted in the inclusion of two additional control variables in each model, yet it yielded nearly identical effect estimates; thus, we opted for the more parsimonious version as our preferred models. All statistical analyses were conducted in STATA SE 15.1 (STATA Corp., College Station, TX).

Ethics. The study protocol was approved by the Bioethics Committee at Universidad San Francisco de Quito (\#2014-
$135 \mathrm{M})$ and the George Washington University Committee on the Human Research Institutional Review Board (IRB\#101355), as well as the Institutional Animal Care and Use Committee at George Washington University (IACUC\#A296).

\section{RESULTS}

Household characteristics. Table 1 describes the characteristics of the 341 households enrolled in the study. Nearly three-quarters of the primary child caretakers were between 18 and 35 years (73.4\%), and almost all were women (94.1\%). Approximately two-thirds of households (60.8\%) were made up of four to six members, and $9.7 \%$ had more than seven

TABLE 1

Descriptive analysis of study households in Yaruqui, Ecuador

\begin{tabular}{|c|c|}
\hline Characteristic & $n(\%)$ \\
\hline \multicolumn{2}{|l|}{ Age of primary caretaker $(n=335)$ (years) } \\
\hline Young (18-35) & $246(73.4)$ \\
\hline Middle (36-55) & $72(21.5)$ \\
\hline Older (56 or older) & $17(5.1)$ \\
\hline \multicolumn{2}{|l|}{ Gender of primary caretaker $(n=341)$} \\
\hline Female & $321(94.1)$ \\
\hline Male & $20(5.9)$ \\
\hline \multicolumn{2}{|l|}{ Household size $(n=339)$} \\
\hline Small (1-3) & $100(29.5)$ \\
\hline Middle (4-6) & $206(60.8)$ \\
\hline Large (7 or more) & $33(9.7)$ \\
\hline \multicolumn{2}{|l|}{ Education of primary caretaker $(n=334)$} \\
\hline Primary education & $133(39.8)$ \\
\hline Pre-secondary education & $166(49.7)$ \\
\hline Secondary or higher & $35(10.5)$ \\
\hline \multicolumn{2}{|l|}{ Neighborhood $(n=341)$} \\
\hline El Centro (urban) & $125(36.7)$ \\
\hline Oton de Velez (semirural) & $65(19.1)$ \\
\hline Chinangachi (semirural) & $70(20.5)$ \\
\hline San Vicente (semirural) & $41(12.0)$ \\
\hline El Tejar (semirural) & $40(11.7)$ \\
\hline \multicolumn{2}{|l|}{ Household assets $(n=341)$} \\
\hline Owns a functioning car & $55(16.1)$ \\
\hline Has Internet access & $62(18.2)$ \\
\hline Has satellite television & 68 (19.9) \\
\hline Owns land & $131(38.4)$ \\
\hline Owns home & $146(42.8)$ \\
\hline \multicolumn{2}{|l|}{ Reported monthly income (USD) ( $n=272)$} \\
\hline $0-100$ & $155(57.0)$ \\
\hline $101-200$ & 105 (38.6) \\
\hline $201-300$ & $7(2.6)$ \\
\hline$>300$ & $5(1.8)$ \\
\hline Presence of flush toilet $(n=341)$ & $333(97.6)$ \\
\hline $\begin{array}{l}\text { A place for handwashing with soap and } \\
\text { water }(n=336)\end{array}$ & $335(99.7)$ \\
\hline Presence of animals $(n=341)$ & $189(55.4)$ \\
\hline Dogs (range, 1-14) & $164(48.9)$ \\
\hline Chickens (range, 1-500) & $118(34.6)$ \\
\hline Guinea pigs (range, 1-100) & $94(27.6)$ \\
\hline Pigs (range, 1-120) & $75(22.0)$ \\
\hline Rabbits (range, 1-24) & $51(15.0)$ \\
\hline Cats (range, 1-6) & $48(14.1)$ \\
\hline Cows (range, 1-6) & $23(6.7)$ \\
\hline Ducks (range, 1-12) & $19(5.6)$ \\
\hline $\begin{array}{l}\text { Other (includes geese, quail, sheep, } \\
\text { goats, horses, and turkeys) }\end{array}$ & $26(7.6)$ \\
\hline $\begin{array}{l}\text { Household member works in food-animal } \\
\text { production }(n=331)\end{array}$ & $22(6.7)$ \\
\hline $\begin{array}{l}\text { Youngest child reported to have diarrhea } \\
\text { in last } 7 \text { days }(n=338)\end{array}$ & $30(9.7)$ \\
\hline $\begin{array}{l}\text { Domestic animal positive for a zoonotic } \\
\text { enteric pathogen }(n=313)\end{array}$ & $107(34.2)$ \\
\hline
\end{tabular}


members. Nearly $90 \%$ of respondents reported having at least a pre-secondary education, equivalent to completion of elementary school. Nearly one-third (36.7\%) of the study population came from El Centro, the neighborhood that was more urban and had fewer animals than the other neighborhoods. About one-fifth of the population reported to have a working car (16.1\%), Internet in their home (18.2\%), and satellite television (19.9\%), and larger proportions reported owning their land (38.4\%) and/or their home (42.8\%). Water, sanitation, and hygiene infrastructure, such as flush toilets and a place for handwashing with soap and water, was present in nearly all households.

Animal ownership and self-reported household health. Among the 341 households surveyed, 189 (55.5\%) reported having at least one domestic animal (domestic pet, livestock, or poultry) living on the immediate property. Dogs were the most common animal species (nearly half of households reported having at least one dog), and the number of dogs owned ranged from one to 14, with a median of 2 dogs (data not shown). Chickens were the dominant food-animal present in households (34.6\%), followed by guinea pigs (27.6\%), pigs (22\%), rabbits (15\%), and cows (6.7\%). A small percentage of the respondents reported having a household member work in food-animal production (6.7\%), either on farms or in processing plants. Of the 189 households with animals, we were able to obtain and analyze stool samples from at least one animal in 178 households and tested a total of 480 unique animals. Thirty children (10\%) were reported to have had diarrhea within the previous 7 days.

Zoonotic enteric pathogen carriage among animals and children. Table 2 presents pathogen carriage among animals $(n=480)$ and children $(n=306)$ from whom we were able to obtain and analyze fecal samples. Among the 306 children in the sample, $112(36.6 \%)$ carried at least one zoonotic enteric pathogen, which represents around $33 \%$ of all households included in the study. We found that 107 households with domestic animals (56.6\%) owned an animal that carried at least one zoonotic enteric pathogen. Among these animals, pigs had the highest prevalence of carriage of one or more zoonotic enteric pathogens $(50.8 \%)$, followed by dogs (45.5\%) and chickens (44.7\%). The prevalence of carriage among the other common domestic animals (rabbits, cats, cows, and ducks) was around onequarter for each species. We found that 41 of the 107 households $(38.3 \%)$ in which at least one animal carried an enteric pathogen also had an infected child. Table 2 shows the animal-pathogen pairs for which there was also a child who tested positive for that pathogen in the same household (marked by the $\ddagger$ symbol). The three pathogens for which this occurred included Giardia, atypical EPEC, and C. jejuni and/or Campylobacter coli. The number of animal-child pairs for which this occurred is shown at the bottom of Table 2.

Overall, the most common pathogen carried by children was Giardia, which was found in the stool samples of $20.3 \%$ of children as well as in $28 \%$ of dogs, $19 \%$ of pigs, and $15 \%$ of rabbits. Giardia was also the most common pathogen to be carried by both animals and children in the same household- 18 of the 41 positive within-household pairs were cases in which Giardia was the shared pathogen, half of which were cases with child-dog pairs. Atypical EPEC was identified in $12.5 \%$ of children and was also found in all species of domestic animals except cats, although the prevalence was generally low among the positive domestic animals (2.4-15.0\%). There were 11 instances in which an animal and child both tested positive for this pathogen within the same household. Eleven children (4.6\%) were found to carry $C$. jejuni and/or C. coli, and all 11 of these cases existing in households in which there was also an animal that tested positive for this pathogen. Carriage prevalence for this pathogen was substantially higher in guinea pigs (39.3\%), chickens (34.3\%), and pigs (29\%). Overall carriage of STEC was low in this study: 16 children $(5.3 \%)$ and three cows $(17.7 \%)$ were positive for STEC. Among all fecal samples collected, only one sample from a pig was positive for Yersinia enterocolitica. Salmonella spp. were found in three children (1.0\%), 13 dogs (1.7\%), and two chickens $(2.0 \%)$.

Domestic animal exposures and child zoonotic enteric pathogen carriage. Table 3 presents estimated PRs and 95\% Cls of the association between animal-related exposures and child enteric pathogen carriage as estimated by the unadjusted and adjusted generalized linear models. The adjusted model includes controls for socioeconomic and demographic variables that demonstrated a statistically

TABLE 2

Presence of zoonotic enteric pathogens in fecal samples from children and domestic animals in Ecuador

\begin{tabular}{|c|c|c|c|c|c|c|c|c|c|}
\hline Zoonotic enteropathogen & $\begin{array}{c}\text { Children } \\
(n=306), n(\%)\end{array}$ & $\begin{array}{c}\text { Dogs } \\
(n=134), n(\%)\end{array}$ & $\begin{array}{c}\text { Chickens } \\
(n=102), n(\%)\end{array}$ & $\begin{array}{c}\text { Guinea pigs } \\
(n=84), n(\%)\end{array}$ & $\begin{array}{c}\text { Pigs } \\
(n=62), n(\%)\end{array}$ & $\begin{array}{c}\text { Rabbits } \\
(n=39), n(\%)\end{array}$ & $\begin{array}{c}\text { Cats } \\
(n=21), n(\%)\end{array}$ & $\begin{array}{c}\text { Cows } \\
(n=21), n(\%)\end{array}$ & $\begin{array}{c}\text { Ducks } \\
(n=17), n(\%)\end{array}$ \\
\hline$\geq 1$ zoonotic enteric pathogen & $112(36.6)$ & $61(45.5)$ & $46(44.7)$ & $37(44.0)$ & $32(50.8)$ & $11(28.2)$ & $5(23.8)$ & $6(28.6)$ & $4(23.5)$ \\
\hline C. jejuni/C. coli & $11(3.6)$ & $10(7.5)$ & $35+(34.3)$ & $33 \dagger(39.3)$ & $18+(29.0)$ & $2(5.1)$ & $4 †(19.0)$ & $2 \dagger(10.0)$ & $2 \dagger(11.8)$ \\
\hline aEPEC & $38(12.5)$ & $13 \dagger(9.7)$ & $9+(8.9)$ & $2 \dagger(2.4)$ & $6 \dagger(9.7)$ & $2 \dagger(5.1)$ & $0(0)$ & $3(15.0)$ & $1 †(5.9)$ \\
\hline Giardia & $62(20.3)$ & $38 \dagger(28.4)$ & $3 \dagger(2.9)$ & $5 \dagger(6.0)$ & $12 \dagger(19.1)$ & $6+(15.4)$ & $2(9.5)$ & $0(0)$ & $0(0)$ \\
\hline Cryptosporidium & $13(4.3)$ & $3(2.2)$ & $3(2.9)$ & $2(2.4)$ & $3(4.8)$ & $1(2.6)$ & $2(9.5)$ & $0(0)$ & $1(0)$ \\
\hline STEC & $16(5.3)$ & $1(1.0)$ & $1(1.1)$ & $1(1.4)$ & $0(0)$ & $0(0)$ & $0(0)$ & $3(17.7)$ & $0(0)$ \\
\hline Y. enterocolitica & $0(0)$ & $0(0)$ & $0(0)$ & $0(0)$ & $1(1.7)$ & $0(0)$ & $0(0)$ & $0(0)$ & $0(0)$ \\
\hline Salmonella spp. & $3(1.0)$ & $13(9.7)$ & $2(2.0)$ & $0(0)$ & $0(0)$ & $0(0)$ & $0(0)$ & $0(0)$ & $0(0)$ \\
\hline \multicolumn{10}{|c|}{ Number of households with positive child-animal pairs } \\
\hline C. jejuni/C. coli & & 0 & 4 & 4 & 1 & 0 & 1 & 1 & 1 \\
\hline aEPEC & & 2 & 2 & 1 & 3 & 2 & 0 & 0 & 1 \\
\hline Giardia & & 9 & 1 & 1 & 3 & 4 & 0 & 0 & 0 \\
\hline
\end{tabular}

C. jejuni = Campylobacterjejuni; C. coli $=$ Campylobacter coli; aEPEC $=$ atypical enteropathogenic $E$. coli; STEC = Shiga toxin-producing E. coli; $Y$. enterocolitica = Yersinia enterocolitica. Data are presented for animals only if there were 15 or more of that particular species. Fewer fecal samples were tested for STEC (dog, $n=105 ;$ chicken, $n=90 ;$ guinea pig, $n=73$; pig, $n=57$; rabbit, $n=31$; cat, $n=19$; cow, $n=17$; and duck, $n=14$ ) and Y. enterocolitica (dog, $n=99$; chicken, $n=83$; guinea pig, $n=71$; pig, $n=58$; rabbit, $n=29$; cat, $n=19$; cow, $n=17$; and duck, $n=13$ ).

$\dagger$ Indicates the presence of animal-pathogen pairs for which there was at least one child with who tested positive for that pathogen in the same household. The number of within-household pairs are presented in the second panel (i.e., there were nine cases in which a dog and child both tested positive for Giardia in the same household). 
TABLE 4

Prevalence of domestic animal exposure and child self-reported diarrhea in last seven days

\begin{tabular}{|c|c|c|c|}
\hline Animal-related exposure $\dagger$ & Prevalence of exposure (\%) $\neq$ & Unadjusted PR (95\% Cl) & Adjusted PR§ (95\% Cl) \\
\hline \multicolumn{4}{|l|}{ Main exposures } \\
\hline Any animals present in/around home & $55.0(186 / 338)$ & $3.27^{\star \star}(1.37,7.80)$ & $2.41(0.64,9.07)$ \\
\hline At least one sub-exposure & $84.0(158 / 186)$ & $2.03(0.50,8.21)$ & $1.79(0.50,6.35)$ \\
\hline Multiple sub-exposures & $38.3(72 / 186)$ & $2.27^{\star}(1.06,4.84)$ & $1.73(0.81,3.70)$ \\
\hline \multicolumn{4}{|l|}{ Sub-exposures } \\
\hline Child regularly interacts with animals & $72.9(137 / 186)$ & $1.40(0.55,3.55)$ & $2.27(0.91,5.67)$ \\
\hline $\begin{array}{l}\text { Animals defecate in areas where child spends } \\
\text { time }\end{array}$ & $12.2(23 / 186)$ & $0.64(0.16,2.57)$ & $0.81(0.24,2.70)$ \\
\hline No handwashing after contact with animals & $12.0(20 / 165)$ & $2.13(0.88,5.16)$ & $0.70(0.19,2.61)$ \\
\hline Consumption of home-raised animal products & $31.4(59 / 186)$ & $2.21^{*}(1.05,4.62)$ & $1.62(0.77,3.39)$ \\
\hline \multicolumn{4}{|c|}{ 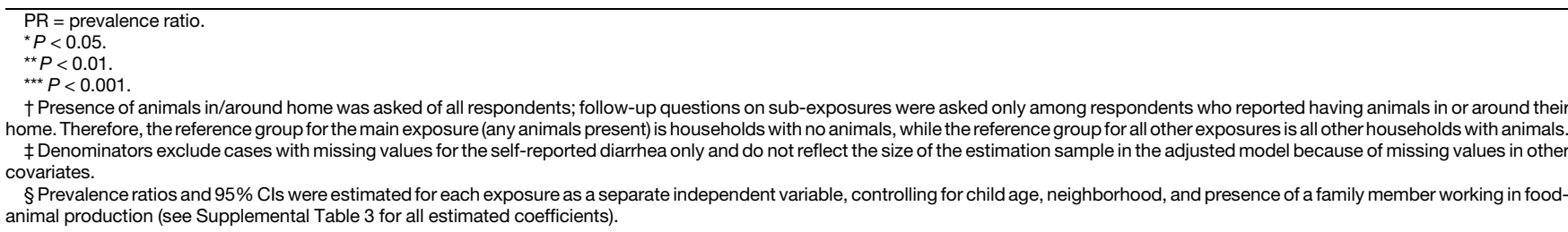 } \\
\hline
\end{tabular}

\section{DISCUSSION}

This study provides evidence that certain environmental exposures related to domestic animals may increase children's risk of carriage of a potentially zoonotic enteric pathogen. We did not find a significant relationship between the overall presence of animals in or around the home and children's risk of colonization of a zoonotic enteric pathogen, yet we did find evidence that children's regular interaction with household animals is a significant risk factor $(P R=1.56$; $95 \% \mathrm{Cl}: 1.00,2.42$ ). This is an important finding, given that nearly three-quarters of households that had animals reported this behavior-the most common of any subexposure we examined. The finding that regular interaction with animals may put children at a higher risk of exposure to fecal contamination is consistent with several recent studies examining zoonotic disease transmission in LMICs. ${ }^{11,45,46}$ Although the risk was elevated, we find that this exposure is not significantly associated with self-reported child diarrhea in the previous seven days ( $\mathrm{PR}=2.27 ; 95 \% \mathrm{Cl}: 0.91,5.67)$, suggesting that many children are asymptomatic carriers of zoonotic enteric pathogens.

A unique contribution of this study is the ability to identify child-animal pairs that tested positive for the same enteric pathogen in the same household. In doing so, we found that Giardia was the most common pathogen found in children and at least one animal in the same household, and that this occurred in 18 households. Furthermore, among these 18 child-animal pairs, half occurred between children and dogs. Although we did not ask respondents in this study about specific child-animal interactions, it is plausible that children are likely to interact more regularly with dogs than other types of animals. Previous qualitative findings from one of the four neighborhoods in the present study (Otón de Velez) supports this hypothesis. ${ }^{47}$ This observation, along with the fact that dogs were the second most common carriers of any enteric pathogen (the prevalence among dogs was $45.5 \%$ ) and the most commonly owned animal overall (nearly half of all households reported owning dogs), suggests that children's interactions with dogs may be driving this result.
Overall, our key findings from this study contribute to mixed literature with respect to the risks associated with household animal ownership. On the one hand, a number of studies demonstrate significant associations between the presence of animals in the home or surrounding areas and the reported incidence or prevalence of diarrhea in humans. ${ }^{48-52}$ Specifically, chickens, pigs, dogs, and cats living in and around the home have been shown to be associated with diarrheal diseases in household members. ${ }^{53-55} \mathrm{~A}$ study of pediatric campylobacteriosis found that household exposure to live chickens was an important risk factor for diarrhea caused by C. jejuni, and a cohort study of pediatric infections with Campylobacter spp. found that the incidence of campylobacteriosis was associated with the presence of poultry inside the home. ${ }^{54,55}$ In Thailand, researchers found non-typhoidal Salmonella in chickens, pigs, dairy cows, farm workers with livestock contact, and children with diarrhea. ${ }^{56}$ Our finding that children regularly interacting with household animals - a behavior that we define as conditional on the household owning domestic animals-is associated with an increased prevalence of diarrhea is consistent with these studies.

However, there is also evidence of null or even negative associations between household animal exposures and related health outcomes. ${ }^{57,58}$ In a surprising finding in Nigeria, Huttly and others ${ }^{59}$ found that households that allowed animals (typically chickens, goats, dogs, and/or cats) in the house reported fewer cases of diarrhea. The authors stated, "the protective effect of animals in the house against diarrhea is not easily explained and may be due to confounding by other factors."

Molecular studies relating microbes in livestock and humans have also been mixed. A study in rural Uganda isolated nonpathogenic $E$. coli from people and livestock in the same communities and showed that the genetic lineages between these isolates collected from domestic animals and humans were "virtually indistinguishable." 60 The same authors also found that nonpathogenic $E$. coli transmission took place between humans, mountain gorillas, and livestock in areas where there was a high level of habitat overlap. ${ }^{61}$ Other studies have found evidence for zoonotic disease transmission between domestic animals to humans, including: 
non-typhoidal Salmonella spp., ${ }^{62}$ Campylobacter spp., ${ }^{63}$ STEC, ${ }^{64}$ Giardia, ${ }^{48}$ Cryptosporidium, ${ }^{65}$ and Y. enterocolitica. 66 By contrast, a study of nonpathogenic $E$. coli strains isolated from children with diarrhea and chickens living in close contact found that the $E$. coli strains in the two groups were distinct. In that study, the authors suggested that children were not susceptible to colonization with $E$. coli from chickens. ${ }^{67}$

Contrary to a case-control study in Kenya, we did not find that reported handwashing of a child's hands after contact with domestic animals was protective. ${ }^{11}$ In fact, contrary to our hypothesis, we found that children who reportedly did not wash their hands after contact with animals were significantly less likely to carry enteric pathogens. This seemingly contradictory finding may have to do with known biases around selfreported handwashing behavior and the fact that only 18 of 152 children living in households reported not washing their hands after contact with animals (for comparison, nearly half of children in the aforementioned study in Kenya did not wash their hands after contact with animals). Given the low number of children in this exposure category, these findings should be interpreted with caution.

In our study, nearly all the child stool samples that were found to be positive for a zoonotic enteric pathogen were solid, suggesting that children were asymptomatic carriers. Surprisingly, asymptomatic carriage of enteropathogens has been found to be common. ${ }^{68}$ There are a number of reasons why children can asymptomatically carry enteric pathogens, including the possibility that symptoms have resided but shedding continues. ${ }^{68}$ In addition, it could be that children have already developed a mild yet strong enough immune response, partly protecting them against infection. Studies have found that when the quantity of a pathogen is considered, stronger positive associations between carriage of a pathogen and symptoms exist. ${ }^{69,70}$ Our study did not quantify the zoonotic pathogens found in the fecal samples, which could have provided further insights.

This study has several limitations. First, the association between domestic animal ownership and zoonotic enteric pathogens was measured using a relatively crude primary measure of exposure: whether or not a household reported having any domestic animals. Studies have shown that the risk of enteric pathogen carriage may increase with the number of animals owned. ${ }^{11}$ While survey respondents in our study were asked to approximate the number of each type of animal they owned, many were unable to provide an estimate, limiting our ability to construct a measure of exposure dosage based on the number of animals. Second, the limited number of children positive for a zoonotic enteric pathogen or who had diarrhea in the last seven days could have affected the ability to detect statistically significant associations. Although we conducted a detailed household survey to capture household characteristics and behaviors that might confound the relationship between exposure to household animals and our outcomes, residual confounding cannot be completely ruled out. Furthermore, the consistent positive association between more rural neighborhoods and child enteric pathogen carriage (see Supplemental Table 1) points to the important role of place-based exposures that we were unable to disentangle at the individual level. It is worth mentioning that the neighborhoods studied were not all visited in the same year, which affects our ability to determine whether the differences in outcomes were due to location-specific factors or potentially significant temporal trends.
Although overall domestic animal ownership does not appear to significantly increase the risk of enteric pathogen carriage or diarrhea among children, we found that a more intense exposure, defined as a child regularly interacting with animals, may put children at an increased risk of being colonized with zoonotic enteropathogens. Specifically, our study finds evidence that child interaction with domestic animals is associated with an increased risk of carriage of zoonotic enteropathogens, many of which appear to be asymptomatic. We find little evidence that overall exposure to household animals or other specific exposures such as animals defecating in common areas or consumption of home-raised animal products elevates this risk. Future studies should focus on unraveling this complex transmission system that involves multiple pathogens coupled with multiple transmission pathways. One important transmission pathway that is not considered in this study but may be especially relevant in this community is transmission through exposure to contaminated produce or other food products that are likely irrigated with water contaminated with animal manure and human wastewater. Qualitative findings from a previous study in Otón de Velez identified crops as a primary source of income for many families, much of which is fertilized using animal manure. This direct application of animal feces and wastewater, along with direct contact between crops and animals, has been identified as a key transmission pathway in previous studies. $^{71,72}$

Based on this study, the community may be the scale in which risk occurs, and other outcome variables such as environmental enteric dysfunction may better determine the role of zoonotic enteric pathogens in the health of children, especially considering the number of subclinical cases that could be still relevant to limiting child growth. ${ }^{73,74}$ The use of advanced molecular methods, including a metagenomics approach and/or whole genome sequence typing, coupled with a prospective study design will be important to more fully characterize the role of animals in causing zoonotic enteric infections in children.

Received September 16, 2019. Accepted for publication February 9, 2020.

Published online March 30, 2020.

Note: Supplemental tables appear at www.ajtmh.org.

Acknowledgments: We greatly appreciate the assistance of Valeria Garzon, the Yaruquí community, and our colleagues in the Microbiology Institute at Universidad San Francisco de Quito, in conducting this research.

Financial support: Research reported in this publication was supported by the National Institutes of Health under award numbers K01 TW 009484 and R01Al135118.

Disclaimer: The content is solely the responsibility of the authors and does not necessarily represent the official views of the National Institutes of Health. The funders had no role in study design, data collection and interpretation, or the decision to submit the work for publication.

Disclosure: To see the study team in action, go to: https://youtu.be/ ji8KQELBB-4.

Authors' addresses: Christopher Lowenstein, Division of Health Policy and Management, University of California, Berkeley School of Public Health, Berkeley, CA, E-mail: chris.lowenstein@berkeley.edu. Jay P. Graham, Division of Environmental Health Sciences, University of California, Berkeley School of Public Health, Berkeley, CA, E-mail: jay.graham@berkeley.edu. Karla Vasco, Department of Microbiology 
\& Molecular Genetics, Michigan State University, East Lansing, MI, E-mail: vascokar@msu.edu. Soledad Sarzosa, Liseth Salinas, Andrea Torres, and Gabriel Trueba, Colegio de Ciencias Biologicas y Ambientales, Microbiology Institute, Universidad San Francisco de Quito, Quito, Ecuador, E-mails: ssarzosa@usfq.edu.ec, Isalinas2@ estud.usfq.edu.ec, atorres@adnbiotech.com, and gtrueba@ usfq.edu.ec. Melissa J. Perry, Department of Environmental and Occupational Health, Milken Institute School of Public Health, The George Washington University, Washington, DC, E-mail: mperry@gwu.edu. Samuel J. Simmens, Department of Biostatistics and Bioinformatics, Milken Institute School of Public Health, The George Washington University, Washington, DC, E-mail: simmens@gwu.edu. Joseph N. S. Eisenberg, Department of Epidemiology, University of Michigan School of Public Health, Ann Arbor, MI, E-mail: jnse@umich.edu.

\section{REFERENCES}

1. Walker CLF, Perin J, Aryee MJ, Boschi-Pinto C, Black RE, 2012. Diarrhea incidence in low-and middle-income countries in 1990 and 2010: a systematic review. BMC Public Health 12: 220.

2. Walker CLF, Rudan I, Liu L, Nair H, Theodoratou E, Bhutta ZA, O’Brien KL, Campbell H, Black RE, 2013. Global burden of childhood pneumonia and diarrhoea. Lancet 381: 1405-1416.

3. Ngure FM, Reid BM, Humphrey JH, Mbuya MN, Pelto G, Stoltzfus RJ, 2014. Water, sanitation, and hygiene (WASH), environmental enteropathy, nutrition, and early child development: making the links. Ann NY Acad Sci 1308: 118-128.

4. Rogawski McQuade ET et al., 2019. Impact of water quality, sanitation, handwashing, and nutritional interventions on enteric infections in rural Zimbabwe: the sanitation hygiene infant nutrition efficacy (SHINE) trial. J Infect Dis 1379: 1-8.

5. Humphrey J, Pickering A, Null C, Winch P, Arnold B, Prendergast A, Njenga S, Rahman M, Ntozini R, Benjamin-Chung J, 2019. The WASH benefits and SHINE trials. Interpretation of findings on linear growth and diarrhoea and implications for policy: perspective of the investigative teams (P10-136-19). Curr Dev Nutr 3: nzz034-P10.

6. Null C, Stewart CP, Pickering AJ, Dentz HN, Arnold BF, Arnold CD, Benjamin-Chung J, Clasen T, Dewey KG, Fernald LC, 2018. Effects of water quality, sanitation, handwashing, and nutritional interventions on diarrhoea and child growth in rural Kenya: a cluster-randomised controlled trial. Lancet Glob Health 6: e316-e329.

7. Ngure FM et al., 2013. Formative research on hygiene behaviors and geophagy among infants and young children and implications of exposure to fecal bacteria. Am J Trop Med Hyg 89: 709-716.

8. Kaur M, Graham JP, Eisenberg JN, 2017. Livestock ownership among rural households and child morbidity and mortality: an analysis of demographic health survey data from 30 subSaharan African countries (2005-2015). Am J Trop Med Hyg 96: 741-748.

9. Boehm AB, Wang D, Ercumen A, Shea M, Harris AR, Shanks OC, Kelty C, Ahmed A, Mahmud ZH, Arnold BF, 2016. Occurrence of host-associated fecal markers on child hands, household soil, and drinking water in rural Bangladeshi households. Environ Sci Technol Lett 3: 393-398.

10. Penakalapati G, Swarthout J, Delahoy MJ, McAliley L, Wodnik B, Levy K, Freeman MC, 2017. Exposure to animal feces and human health: a systematic review and proposed research priorities. Environ Sci Technol 51: 11537-11552.

11. Conan A, O'Reilly CE, Ogola E, Ochieng JB, Blackstock AJ, Omore R, Ochieng L, Moke F, Parsons MB, Xiao L, 2017. Animal-related factors associated with moderate-to-severe diarrhea in children younger than five years in western Kenya: a matched case-control study. PLoS Negl Trop Dis 11: e0005795.

12. Hale CR, Scallan E, Cronquist AB, Dunn J, Smith $K$, Robinson $T$, Lathrop S, Tobin-D'Angelo M, Clogher P, 2012. Estimates of enteric illness attributable to contact with animals and their environments in the United States. Clin Infect Dis 54(Supp/ 5): S472-S479.
13. Goodwin R, Schley D, Lai K-M, Ceddia GM, Barnett J, Cook N, 2012. Interdisciplinary approaches to zoonotic disease. Infect Dis Rep 4: 37.

14. Croll NA, Cross JH, 2013. Human Ecology and Infectious Diseases. New York, NY: Academic Press.

15. Perin J, Thomas A, Oldja L, Ahmed S, Parvin T, Bhuyian SI, Sarker B, Biswas SK, Faruque AS, Sack RB, 2016. Geophagy is associated with growth faltering in children in rural Bangladesh. J Pediatr 178: 34-39.e1.

16. George CM, Oldja L, Biswas S, Perin J, Lee GO, Kosek M, Sack RB, Ahmed S, Haque R, Parvin T, 2015. Geophagy is associated with environmental enteropathy and stunting in children in rural Bangladesh. Am J Trop Med Hyg 92: 1117-1124.

17. Lee G, Pan W, Yori PP, Olortegui MP, Tilley D, Gregory M, Oberhelman R, Burga R, Chavez CB, Kosek M, 2013. Symptomatic and asymptomatic Campylobacter infections associated with reduced growth in Peruvian children. PLoS Negl Trop Dis 7: e2036.

18. Schriewer A, Odagiri M, Wuertz S, Misra PR, Panigrahi P, Clasen $\mathrm{T}$, Jenkins MW, 2015. Human and animal fecal contamination of community water sources, stored drinking water and hands in rural India measured with validated microbial source tracking assays. Am J Trop Med Hyg 93: 509-516.

19. Conan A, Goutard FL, Sorn S, Vong S, 2012. Biosecurity measures for backyard poultry in developing countries: a systematic review. BMC Vet Res 8: 240.

20. Ali J, 2007. Livestock sector development and implications for rural poverty alleviation in India. Livest Res Rural Dev 19: 1-15.

21. Leroy JL, Frongillo EA, 2007. Can interventions to promote animal production ameliorate undernutrition? J Nutr 137: 2311-2316.

22. Zambrano LD, Levy K, Menezes NP, Freeman MC, 2014. Human diarrhea infections associated with domestic animal husbandry: a systematic review and meta-analysis. Trans $R$ Soc Trop Med Hyg 108: 313-325.

23. Hutchison ML, Walters LD, Avery SM, Synge BA, Moore A, 2004. Levels of zoonotic agents in British livestock manures. Lett Appl Microbiol 39: 207-214.

24. Thompson RCA, Palmer CS, O'Handley R, 2008. The public health and clinical significance of Giardia and Cryptosporidium in domestic animals. Vet $J$ 177: 18-25.

25. Keen JE, Wittum TE, Dunn JR, Bono JL, Durso LM, 2006. Shigatoxigenic Escherichia coli $\mathrm{O} 157$ in agricultural fair livestock, United States. Emerg Infect Dis 12: 780-786.

26. McNally A, Cheasty T, Fearnley C, Dalziel R, Paiba G, Manning G, Newell D, 2004. Comparison of the biotypes of Yersinia enterocolitica isolated from pigs, cattle and sheep at slaughter and from humans with yersiniosis in Great Britain during 1999-2000. Lett Appl Microbiol 39: 103-108.

27. Kotloff KL, Nataro JP, Blackwelder WC, Nasrin D, Farag TH, Panchalingam S, Wu Y, Sow SO, Sur D, Breiman RF, 2013. Burden and aetiology of diarrhoeal disease in infants and young children in developing countries (the Global Enteric Multicenter Study, GEMS): a prospective, case-control study. Lancet 382: 209-222.

28. Tobin MR, Goldshear JL, Price LB, Graham JP, Leibler JH, 2015. A framework to reduce infectious disease risk from urban poultry in the United States. Public Health Rep 130: 380-391.

29. Scallan E, Hoekstra R, Mahon B, Jones T, Griffin P, 2015. An assessment of the human health impact of seven leading foodborne pathogens in the United States using disability adjusted life years. Epidemiol Infect 143: 2795-2804.

30. Gomes TA, Yamamoto D, Vieira MA, Hernandes RT, 2016. Atypical enteropathogenic Escherichia coli. Escherichia Coli in the Americas. Cham, Switzerland: Springer, 77-96.

31. Vasco K, Graham JP, Trueba G, 2016. Detection of zoonotic enteropathogens in children and domestic animals in a semirural community in Ecuador. Appl Environ Microbiol 82: 4218-4224.

32. Curtis V, Schmidt W, Luby S, Florez R, Touré O, Biran A, 2011. Hygiene: new hopes, new horizons. Lancet Infect Dis 11: 312-321.

33. Holt HR, Inthavong P, Khamlome B, Blaszak K, Keokamphe C, Somoulay V, Phongmany A, Durr PA, Graham K, Allen J, 2016. Endemicity of zoonotic diseases in pigs and humans in lowland 
and upland Lao PDR: identification of socio-cultural risk factors. PLoS Negl Trop Dis 10: e0003913.

34. El-Tras WF, Holt H, Tayel A, El-Kady N, 2015. Campylobacter infections in children exposed to infected backyard poultry in Egypt. Epidemiol Infect 143: 308-315.

35. Oberhelman RA, Gilman RH, Sheen P, Cordova J, Zimic M, Cabrera L, Meza R, Perez J, 2006. An intervention-control study of corralling of free-ranging chickens to control Campylobacter infections among children in a Peruvian periurban shantytown. Am J Trop Med Hyg 74: 1054-1059.

36. Osbjer K, Boqvist S, Sokerya S, Chheng K, San S, Davun H, Rautelin H, Magnusson U, 2016. Risk factors associated with Campylobacter detected by PCR in humans and animals in rural Cambodia. Epidemiol Infect 144: 2979-2988.

37. Weis BK, Balshaw D, Barr JR, Brown D, Ellisman M, Lioy P, Omenn G, Potter JD, Smith MT, Sohn L, 2005. Personalized exposure assessment: promising approaches for human environmental health research. Environ Health Perspect 113: 840-848.

38. Howe LD, Galobardes B, Matijasevich A, Gordon D, Johnston D, Onwujekwe O, Patel R, Webb EA, Lawlor DA, Hargreaves JR, 2012. Measuring socio-economic position for epidemiological studies in low-and middle-income countries: a methods of measurement in epidemiology paper. Int $J$ Epidemiol 41: 871-886.

39. Arnold BF, Galiani S, Ram PK, Hubbard AE, Briceño B, Gertler PJ, Colford JM Jr., 2013. Optimal recall period for caregiverreported illness in risk factor and intervention studies: a multicountry study. Am J Epidemiol 177: 361-370.

40. Karns J, Van Kessel J, McClusky B, Perdue M, 2007. Incidence of Escherichia coli O157: h7 and E. coli virulence factors in US bulk tank milk as determined by polymerase chain reaction. J Dairy Sci 90: 3212-3219.

41. Tornieporth NG, John J, Salgado K, de Jesus P, Latham E, Melo MC, Gunzburg ST, Riley LW, 1995. Differentiation of pathogenic Escherichia coli strains in Brazilian children by PCR. J Clin Microbiol 33: 1371-1374.

42. Pollard D, Johnson W, Lior H, Tyler S, Rozee K, 1990. Rapid and specific detection of verotoxin genes in Escherichia coli by the polymerase chain reaction. J Clin Microbiol 28: 540-545.

43. Kim S, Frye JG, Hu J, Fedorka-Cray PJ, Gautom R, Boyle DS, 2006. Multiplex PCR-based method for identification of common clinical serotypes of Salmonella enterica subsp. enterica. J Clin Microbiol 44: 3608-3615.

44. Persson S, Olsen KE, 2005. Multiplex PCR for identification of Campylobacter coli and Campylobacter jejuni from pure cultures and directly on stool samples. J Med Microbiol 54: 1043-1047.

45. Fuhrmeister ER, Ercumen A, Pickering AJ, Jeanis KM, Ahmed M, Brown S, Arnold BF, Hubbard AE, Alam M, Sen D, 2019. Predictors of enteric pathogens in the domestic environment from human and animal sources in rural Bangladesh. Environ Sci Technol 53: 10023-10033.

46. Budge S, Hutchings P, Parker A, Tyrrel S, Tulu T, Gizaw M, Garbutt C, 2019. Do domestic animals contribute to bacterial contamination of infant transmission pathways? Formative evidence from Ethiopia. J Water Health 17: 655-669.

47. Lowenstein C, Waters WF, Roess A, Leibler JH, Graham JP, 2016. Animal husbandry practices and perceptions of zoonotic infectious disease risks among livestock keepers in a rural parish of Quito, Ecuador. Am J Trop Med Hyg 95: 1450-1458.

48. Cruz JR, Cano F, Caceres P, Chew F, Pareja G, 1988. Infection and diarrhea caused by Cryptosporidium sp. among Guatemalan infants. J Clin Microbiol 26: 88-91.

49. Huang JL et al., 2009. Epidemiological surveillance of Campylobacter jejuni in chicken, dairy cattle and diarrhoea patients. Epidemiol Infect 137: 1111-1120.

50. Pathela P, Zahid Hasan K, Roy E, Huq F, Kasem Siddique A, Bradley Sack R, 2006. Diarrheal illness in a cohort of children 0-2 years of age in rural Bangladesh: I. Incidence and risk factors. Acta Paediatr 95: 430-437.

51. Coles CL, Levy A, Dagan R, Deckelbaum RJ, Fraser D, 2009. Risk factors for the initial symptomatic giardia infection in a cohort of young Arab-Bedouin children. Ann Trop Paediatr 29: 291-300.
52. Bukenya GB, Nwokolo N, 1991. Compound hygiene, presence of standpipe and the risk of childhood diarrhoea in an urban settlement of Papua New Guinea. Int J Epidemiol 20: 534-539.

53. Black RE, Lopez de Romana G, Brown KH, Bravo N, Bazalar OG, Kanashiro HC, 1989. Incidence and etiology of infantile diarrhea and major routes of transmission in Huascar, Peru. Am J Epidemiol 129: 785-799.

54. Georges-Courbot MC, Cassel-Beraud AM, Gouandjika I, Monges J, Georges AJ, 1990. A cohort study of enteric campylobacter infection in children from birth to two years in Bangui (Central African Republic). Trans R Soc Trop Med Hyg 84: 122-125.

55. Grados O, Bravo N, Black RE, Butzler JP, 1988. Paediatric campylobacter diarrhoea from household exposure to live chickens in Lima, Peru. Bull World Health Organ 66: 369-374.

56. Padungtod $P$, Kaneene JB, 2006. Salmonella in food animals and humans in northern Thailand. Int J Food Microbiol 108: 346-354

57. Iqbal J, Munir MA, Khan MA, 1999. Cryptosporidium infection in young children with diarrhea in Rawalpindi, Pakistan. Am J Trop Med Hyg 60: 868-870.

58. Knee J, Sumner T, Adriano Z, Berendes D, de Bruijn E, Schmidt W-P, Nalá R, Cumming O, Brown J, 2018. Risk factors for childhood enteric infection in urban Maputo, Mozambique: a cross-sectional study. PLoS Negl Trop Dis 12: e0006956.

59. Huttly SR, Blum D, Kirkwood BR, Emeh RN, Feachem RG, 1987. The epidemiology of acute diarrhoea in a rural community in Imo state, Nigeria. Trans $R$ Soc Trop Med Hyg 81: 865-870.

60. Rwego IB, Gillespie TR, Isabirye-Basuta G, Goldberg TL, 2008. High rates of Escherichia coli transmission between livestock and humans in rural Uganda. J Clin Microbiol 46: 3187-3191.

61. Rwego IB, Isabirye-Basuta G, Gillespie TR, Goldberg TL, 2008. Gastrointestinal bacterial transmission among humans, mountain gorillas, and livestock in Bwindi Impenetrable National Park, Uganda. Conserv Biol 22: 1600-1607.

62. Hoelzer K, Switt AIM, Wiedmann M, 2011. Animal contact as a source of human non-typhoidal salmonellosis. Vet Res 42: 34.

63. Sahin O, Fitzgerald C, Stroika S, Zhao S, Sippy RJ, Kwan P, Plummer PJ, Han J, Yaeger MJ, Zhang Q, 2012. Molecular evidence for zoonotic transmission of an emergent, highly pathogenic Campylobacter jejuni clone in the United States. J Clin Microbiol 50: 680-687.

64. Leomil L, de Castro AFP, Krause G, Schmidt H, Beutin L, 2005. Characterization of two major groups of diarrheagenic Escherichia coli $\mathrm{O} 26$ strains which are globally spread in human patients and domestic animals of different species. Fems Microbiol Lett 249: 335-342.

65. Budu-Amoako E, Greenwood S, Dixon B, Sweet L, Ang L, Barkema H, McClure J, 2012. Molecular epidemiology of Cryptosporidium and Giardia in humans on Prince Edward Island, Canada: evidence of zoonotic transmission from cattle. Zoonoses Public Health 59: 424-433.

66. Fredriksson-Ahomaa M, Stolle A, Korkeala H, 2006. Molecular epidemiology of Yersinia enterocolitica infections. FEMS Immunol Med Microbiol 47: 315-329.

67. Kariuki S, Gilks C, Kimari J, Obanda A, Muyodi J, Waiyaki P, Hart CA, 1999. Genotype analysis of Escherichia coli strains isolated from children and chickens living in close contact. Appl Environ Microbiol 65: 472-476.

68. Enserink R, Scholts R, Bruijning-Verhagen P, Duizer E, Vennema $\mathrm{H}$, de Boer R, Kortbeek T, Roelfsema J, Smit H, Kooistra-Smid $M, 2014$. High detection rates of enteropathogens in asymptomatic children attending day care. PLoS One 9: e89496.

69. Levine MM, Robins-Browne RM, 2012. Factors that explain excretion of enteric pathogens by persons without diarrhea. Clin Infect Dis 55(Suppl 4): S303-S311.

70. Platts-Mills JA, Gratz J, Mduma E, Svensen E, Amour C, Liu J, Maro A, Saidi Q, Swai N, Kumburu H, 2014. Association between stool enteropathogen quantity and disease in Tanzanian children using TaqMan array cards: a nested case-control study. Am J Trop Med Hyg 90: 133-138.

71. Islam M, Doyle MP, Phatak SC, Millner P, Jiang X, 2005. Survival of Escherichia coli O157: h7 in soil and on carrots and onions grown in fields treated with contaminated manure composts or irrigation water. Food Microbiol 22: 63-70. 
72. Guan TY, Holley RA, 2003. Pathogen survival in swine manure environments and transmission of human enteric illness-a review. J Environ Qual 32: 383-392.

73. Crane RJ, Jones KD, Berkley JA, 2015. Environmental enteric dysfunction: an overview. Food Nutr Bull 36(1 Suppl): S76-S87.
74. George CM, Oldja L, Biswas SK, Perin J, Lee GO, Ahmed S, Haque R, Sack RB, Parvin T, Azmi IJ, 2015. Fecal markers of environmental enteropathy are associated with animal exposure and caregiver hygiene in Bangladesh. Am J Trop Med Hyg 93: 269-275. 